Research Article

\title{
Refinement of a Deflection Basin Area Index Method for Rigid Pavement
}

\author{
Jin Zhang $\mathbb{D}^{1}{ }^{1}$ Qiuzhen Lv, ${ }^{1}$ Wei Shi, ${ }^{1}$ Guangsheng Li, ${ }^{1}$ and Jiafeng Zhang ${ }^{2}$ \\ ${ }^{1}$ School of Civil Engineering, Qingdao University of Technology, Qingdao 266033, China \\ ${ }^{2}$ Shanghai CAAC New Era Airport Design \& Research Institute Co., Ltd., Shanghai 200120, China
}

Correspondence should be addressed to Jin Zhang; zhangjin@qut.edu.cn

Received 25 April 2021; Accepted 12 June 2021; Published 22 June 2021

Academic Editor: Zhigang Tao

Copyright (c) 2021 Jin Zhang et al. This is an open access article distributed under the Creative Commons Attribution License, which permits unrestricted use, distribution, and reproduction in any medium, provided the original work is properly cited.

The accuracy of the prediction and reliability of the deflection basin area index method for rigid pavement heavily depend on the sensor layout scheme and the calculation theory. A total of 154 groups of deflection data were generated by the finite element software in different conditions, and the simulated results were in good agreement with the analytical solutions of thin plates on elastic foundation. The accuracy of several types of deflection basin area index methods was assessed with the database of pavement deflection results. It is found that, apart from densifying the distal sensor layouts locally, replacing the deflection value of a specific point with the average of all measured points in the deflection basin area index was also an effective measure to improve the back-calculation accuracy of pavement structural parameters up to $40 \%$. Finally, a new deflection basin area index method was proposed based on the deflection database with the regression analysis. Comparisons between the theoretical calculations of several models and the practical deflection data of an airport in northern China revealed that the newly proposed method performs better on the back-calculation accuracy and efficiency, which can provide a valuable guideline for the practical engineering in the design.

\section{Introduction}

Sufficient load capacities are essential for the airport runway due to the considerable impact loads during the aircraft landing. The deflection, total deformations of the airport pavement under the load, is a critical parameter to reflect the overall load-bearing capacities of pavement structures. The heavy weight deflectometer (HWD) test, a vital technology for the strength design and performance evaluation of pavement structures, has been widely adopted to determine the deflection value [1-4]. In general, the primary methods for parameter back-calculation of the pavements' structural performance based on deflection values can be classified as follows.

The intelligent optimization method has been developed to find out the optimal solution of pavement structural parameters iteratively, such as neural network algorithm and genetic algorithm $[5,6]$. However, the accuracy of these methods heavily depends on the reliability of the algorithm and the calibration of some internal parameters [7, 8]. Darter et al. [9] have developed the back-calculation technique, like the point-by-point fitting method, to determine the optimal solution by comparing the objective function results of calibration error with the actual deflection basin through an iterative approach. Nevertheless, low efficiency was detected with this method in the iterative process. Besides, Sun et al. [10] have reported that the inherent information of the inert point on deflection curves remained constant regardless of the variations of resilient modulus of pavement slabs. Although the back-calculation of pavement structural parameters can be conducted once the specific inert point was obtained, the deterministic process of this point was relatively complicated $[10,11]$.

Compared with the back-calculation methods, the derived index method of the deflection basin [12] has been widely recognized by many researchers and engineers mainly due to the simplification of the back-calculation process. The method is also adopted by Chinese code MH/T 
5024-2009 [13] and the U.S. Federal Aviation Administration [14] for the back-calculation of pavement structure parameters. This method simplifies the back-calculation process by constructing a deflection basin area index, which includes fitting formula method, back-calculation software method, and graphic method. However, related studies $[15,16]$ have revealed that the normalization of the basin area index during the aforementioned constructional process with only an assigned measurement point will cause the inferior accuracy and higher variability. To incorporate the effect of different measuring points, Lin et al. [15] have improved the back-calculation method by minimizing the calculated errors of the objective function, but the efficiency has been significantly influenced. However, either the calculation accuracy of these methods is not up to the standard, or the calculation process is too complex, which is not conducive to direct engineering application.

With this background, the finite element $(\mathrm{FE})$ simulation was first applied to generate deflection information under different working conditions. Then, the error analysis was systematically conducted for the existing deflection basin area index methods based on the assembled database, and a new improved approach was developed in this study for practical engineering. By comparing with the measured data of an airport, the prediction accuracy of this method and other selection methods for back-calculation results were evaluated. The result shows that the improved deflection basin area index method has the advantages of simple calculation and high accuracy. In practical engineering application, it can not only save time but also achieve fast and accurate results, which is of great significance.

\section{Finite Element Simulation}

Considering that multiple variables cannot be considered simultaneously in a practical engineering, the effect of different conditions on the structures cannot be comprehensively estimated. Moreover, the test setup with high costs and measurement strategy may have a great impact on the accuracy of test results. Over the past decades, the FE technique has become increasingly popular in academic researches [17-20] because it can solve the problems that cannot be realized in engineering field. Thus, the finite element software was adopted to simulate the deflections of airport pavement structures under varied working conditions in this study. Studies on parameters were also conducted with the verified FE model for the following theoretical analysis.

2.1. Parameter Setting. The sectional size of the pavement slab was set as $30 \mathrm{~m} \times 30 \mathrm{~m}$ to reduce the influence of edge effect on the simulation because there are no relationships between the deflection value and the slab size for the position beyond $0.7 \mathrm{~m}$ away from the slab edge [21]. As per the Chinese code MH/T 5024-2009 [13], some basic parameters of the model were presented as follows: Poisson's ratio $(u=0.15)$; the elastic modulus of the thin concrete plate $(32 \mathrm{GPa})$.
2.2. Boundary Conditions and Mesh. The spring foundation was added at the bottom surface of pavement slab, and the modulus of subgrade reaction was defined as $k$ to simulate the equivalent reaction modulus of different soil layers under the pavement in actual engineering. Circular uniform load ( $0.15 \mathrm{~m}$ in radius) was applied on the upper surface of the model. No constraints were arranged on the other four sides. The static load of $1.5 \mathrm{MPa}$ was used to simulate the maximum impact load produced by HWD test to obtain the corresponding deflection values according to the literature [19]. The free tetrahedral mesh was chosen, and the mesh element size was smaller than the thickness of the pavement slab $h$.

2.3. FE Model Results. One hundred and fifty-four groups of test data (see Table 1) were generated by uniformly extracting the deflection value at the position of $0 \mathrm{~cm}, 20 \mathrm{~cm}$, $30 \mathrm{~cm}, 45 \mathrm{~cm}, 60 \mathrm{~cm}, 90 \mathrm{~cm}, 120 \mathrm{~cm}, 150 \mathrm{~cm}$, and $180 \mathrm{~cm}$ away from the load center of the model. In this process, the value of the modulus of subgrade reaction $k$ and the thickness of pavement slab $h$ are continuously changed. Figure 1 shows the layout of the measuring points mentioned above. Figure 2 shows the simulation results of pavement slab with $28 \mathrm{~mm}$ in thickness and the modulus of subgrade reaction of $125 \mathrm{MN} / \mathrm{m}^{3}$. Furthermore, the value of $h$ can be determined from the suggested slab thickness for the FE simulation provided by Cheng et al. [19]. The empirical value of subgrade reaction $k$ can be referred to as the Chinese code GB 50307-2012 [22], and the selected ranges of $h$ and $k$ are presented in Table 2. To facilitate the following discussion, each working condition is given a name composed of letters and numbers. The first letter and the subsequent numbers represent the thickness of the slab (unit: $\mathrm{mm}$ ). The second letter and the corresponding number stand for the modulus of subgrade reaction (unit: $\mathrm{MN} / \mathrm{m}^{3}$ ). For example, H28K125 represents the working condition with the pavement thickness of $28 \mathrm{~mm}$ and modulus of subgrade reaction of $125 \mathrm{MN} / \mathrm{m}^{3}$. N represents sensors in Figure 1.

\subsection{FE Model Verification}

2.4.1. Winkler Foundation Model. Chen et al. [20] have found that the Winkler foundation model performs better than the elastic half-space foundation model in calculating the structural responses of the pavement. It is assumed that the pressure $p$ at one point on the foundation surface is proportional to the settlement $w$ at the same point in the Winkler foundation model, and the pressure $p$ is also independent of the pressure from surrounding points. The relationship between $p$ and $w$ can be presented as $p=k \cdot w$, which means that every single point of the foundation is supported by a spring, which works separately at different locations.

The analytical equation of the one thin slab deflection value predicted by the Winkler foundation model under uniformly distributed circular load is shown in equation (1) [23], which provides a reliable standard for the verification of deflection results obtained from the FE model. 


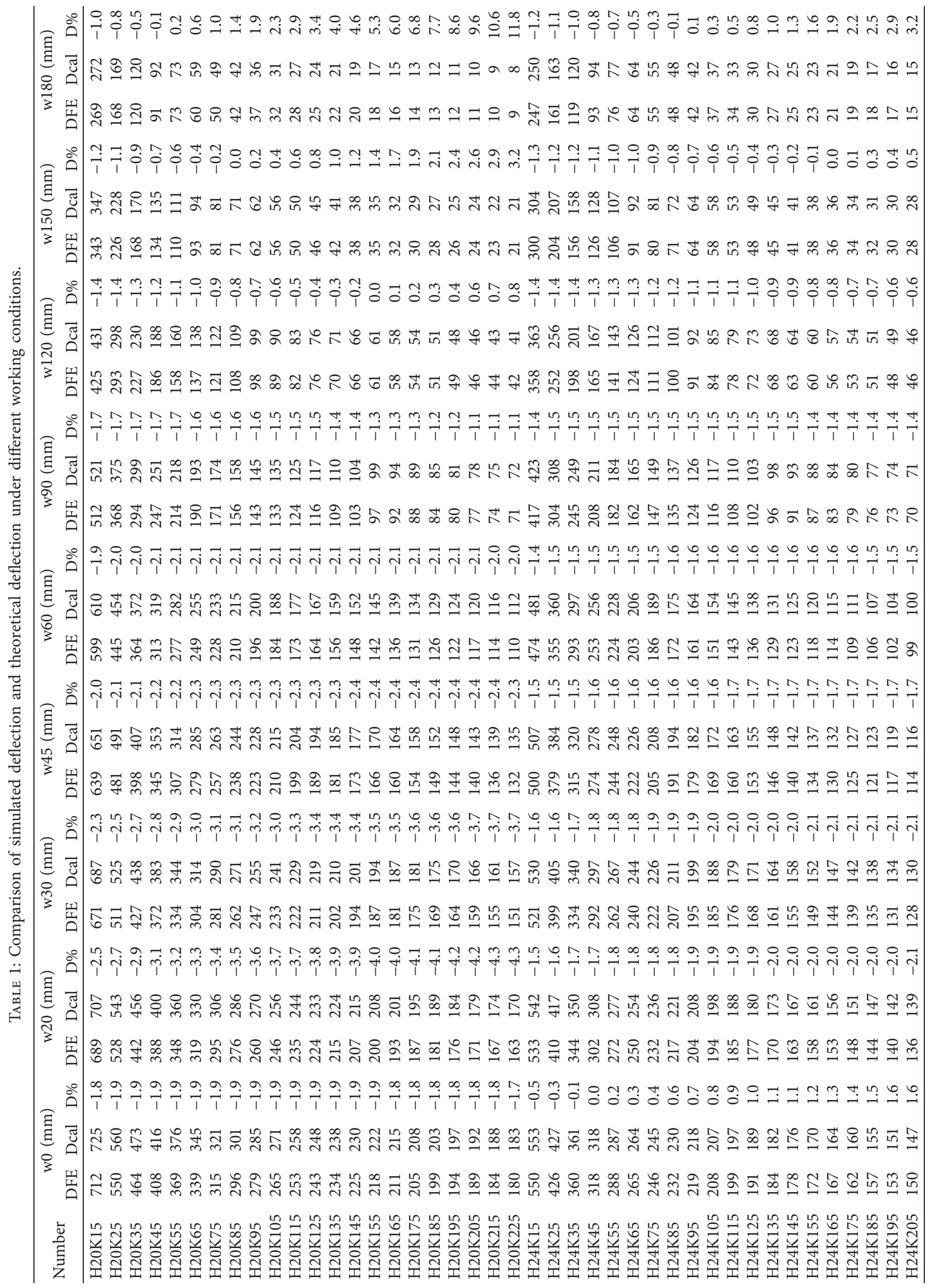




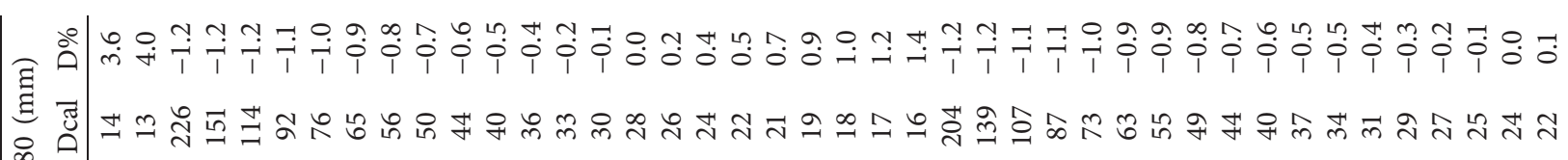

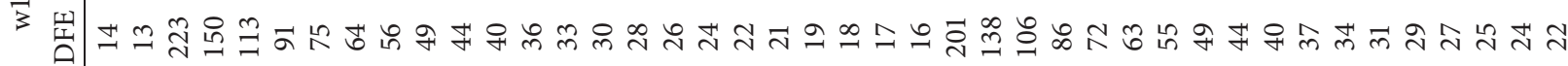

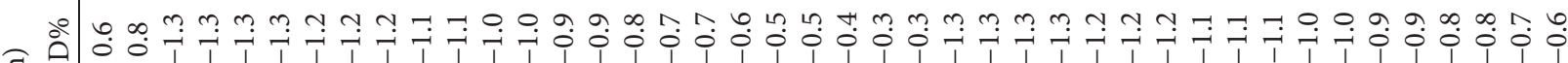

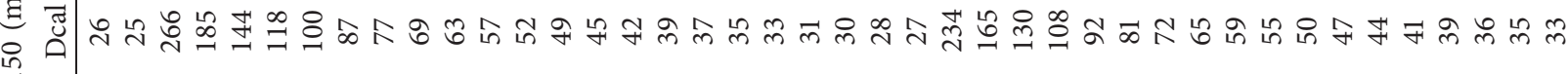

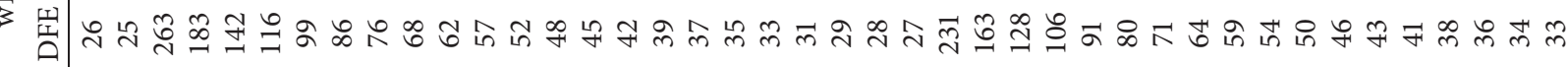

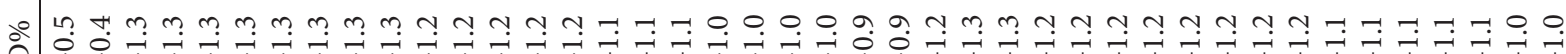
อิดी

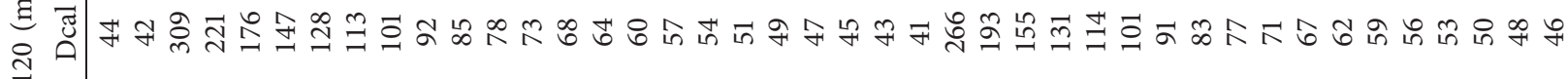

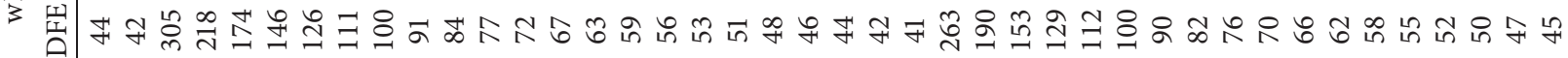

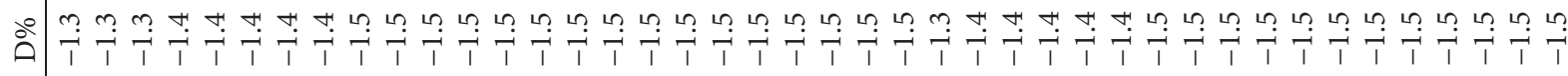
द्

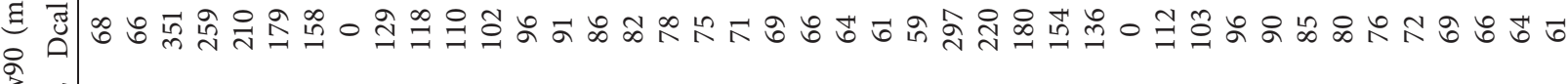

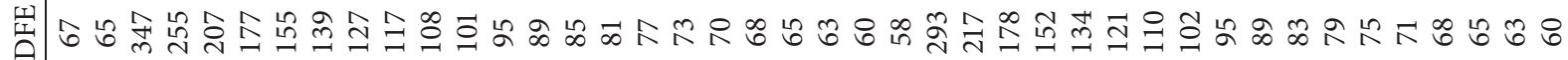

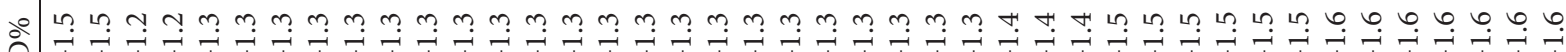

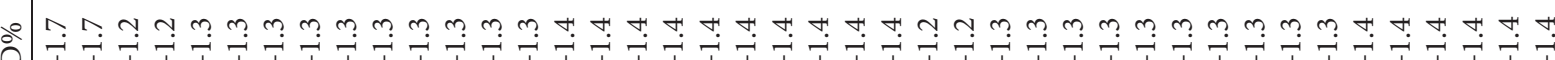
द 응

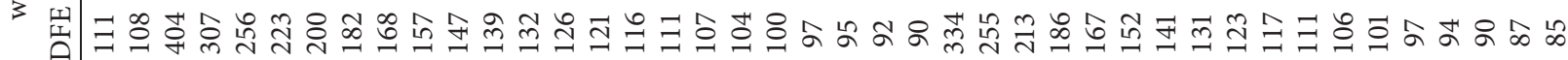
คำ

ऊ

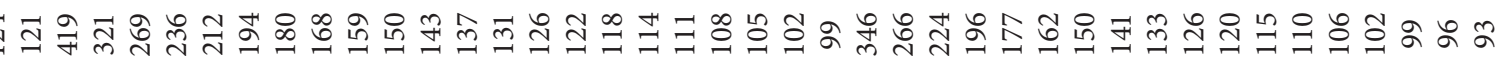

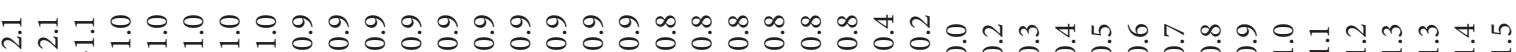

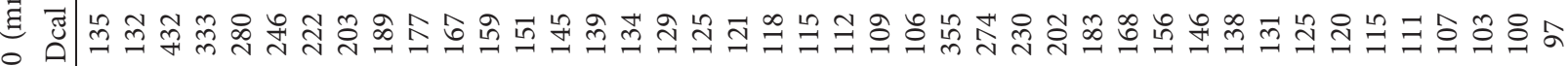

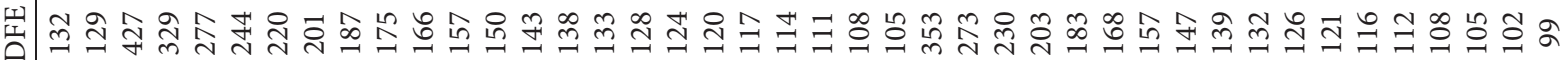

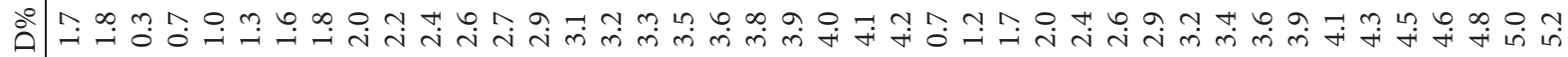




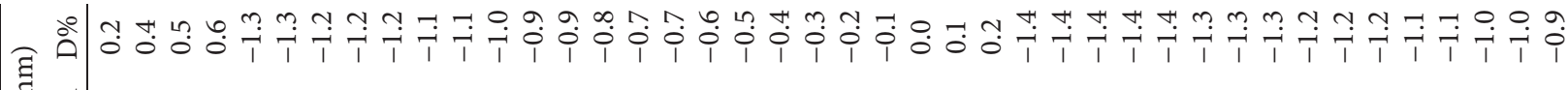

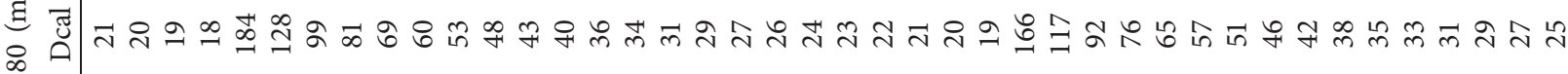

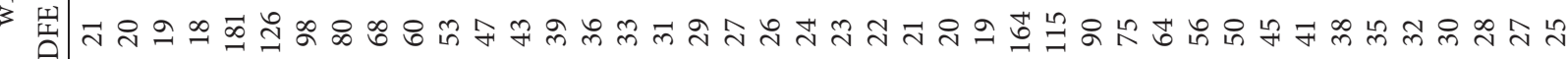
6 !

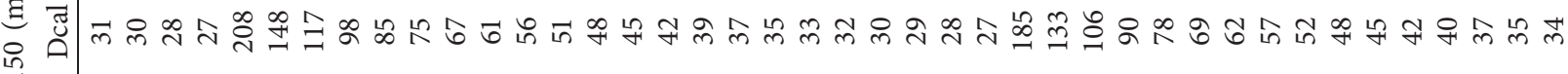

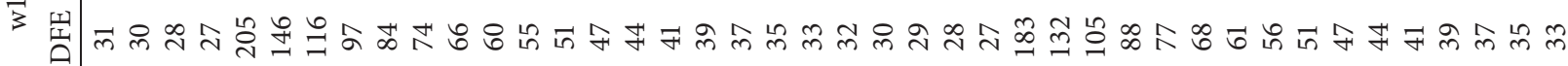

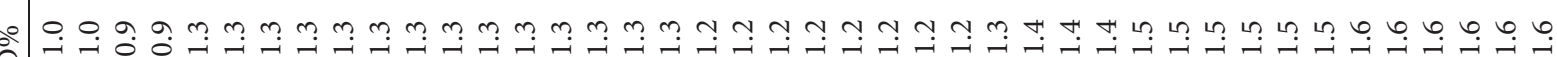

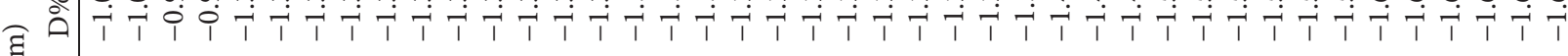

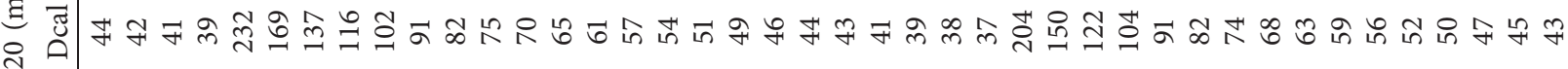

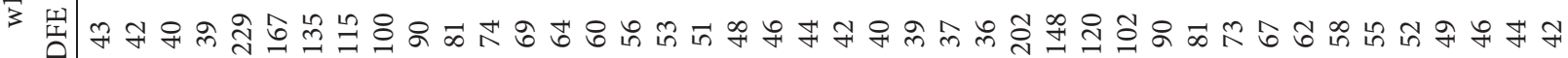

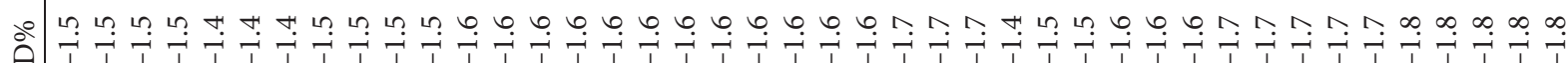

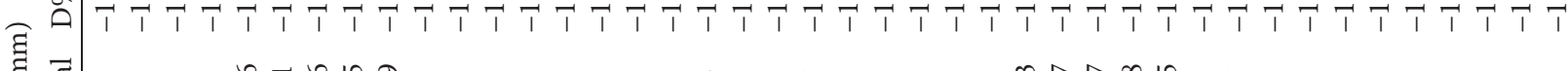

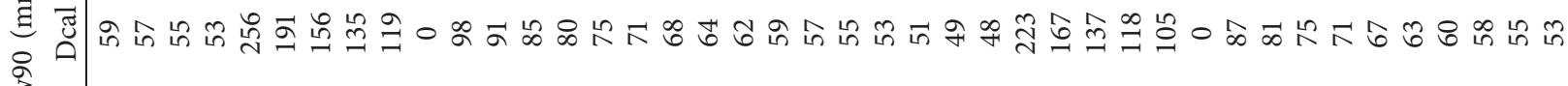

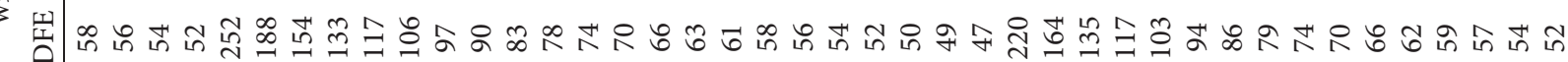

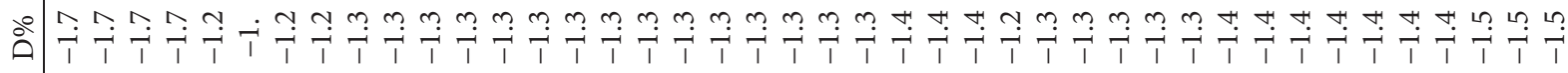
还

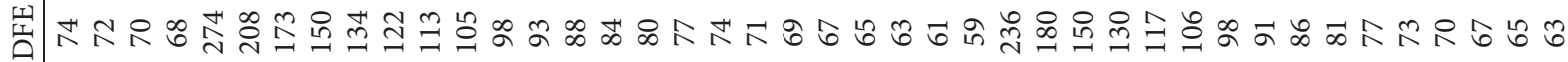

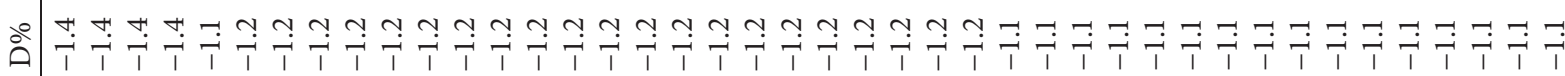
๓ 留

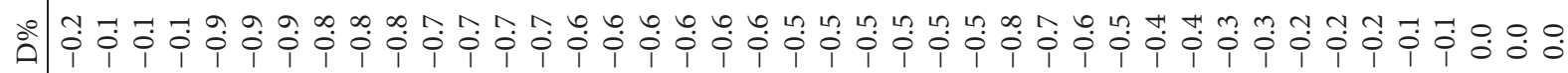
窟 है 武 遂 ล

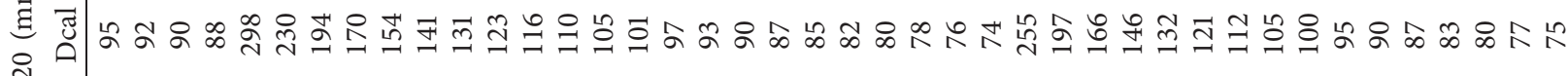

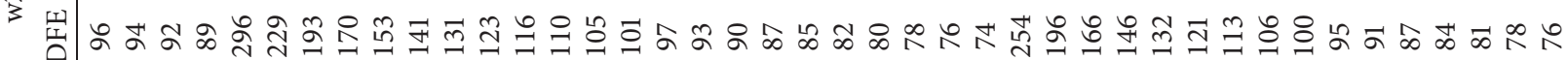

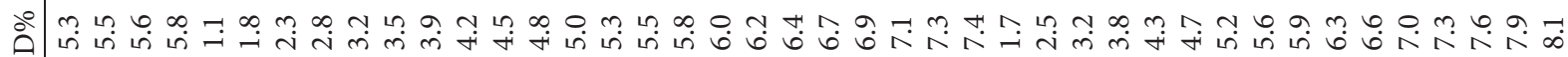

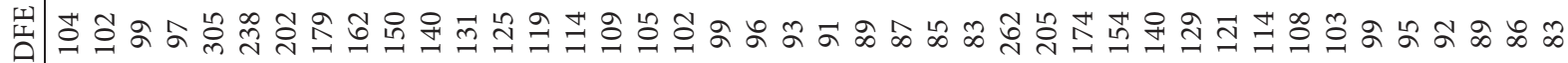

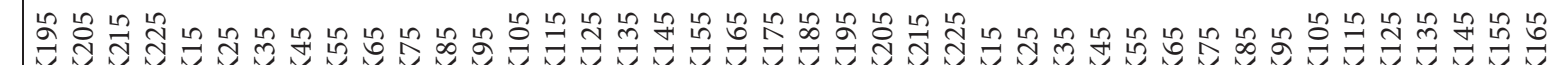

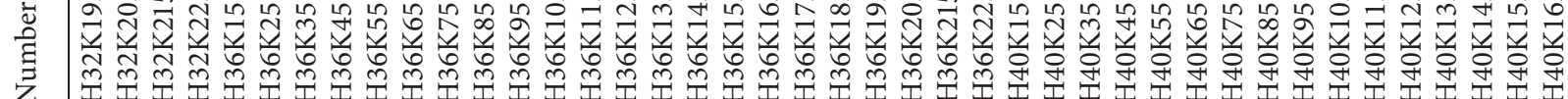




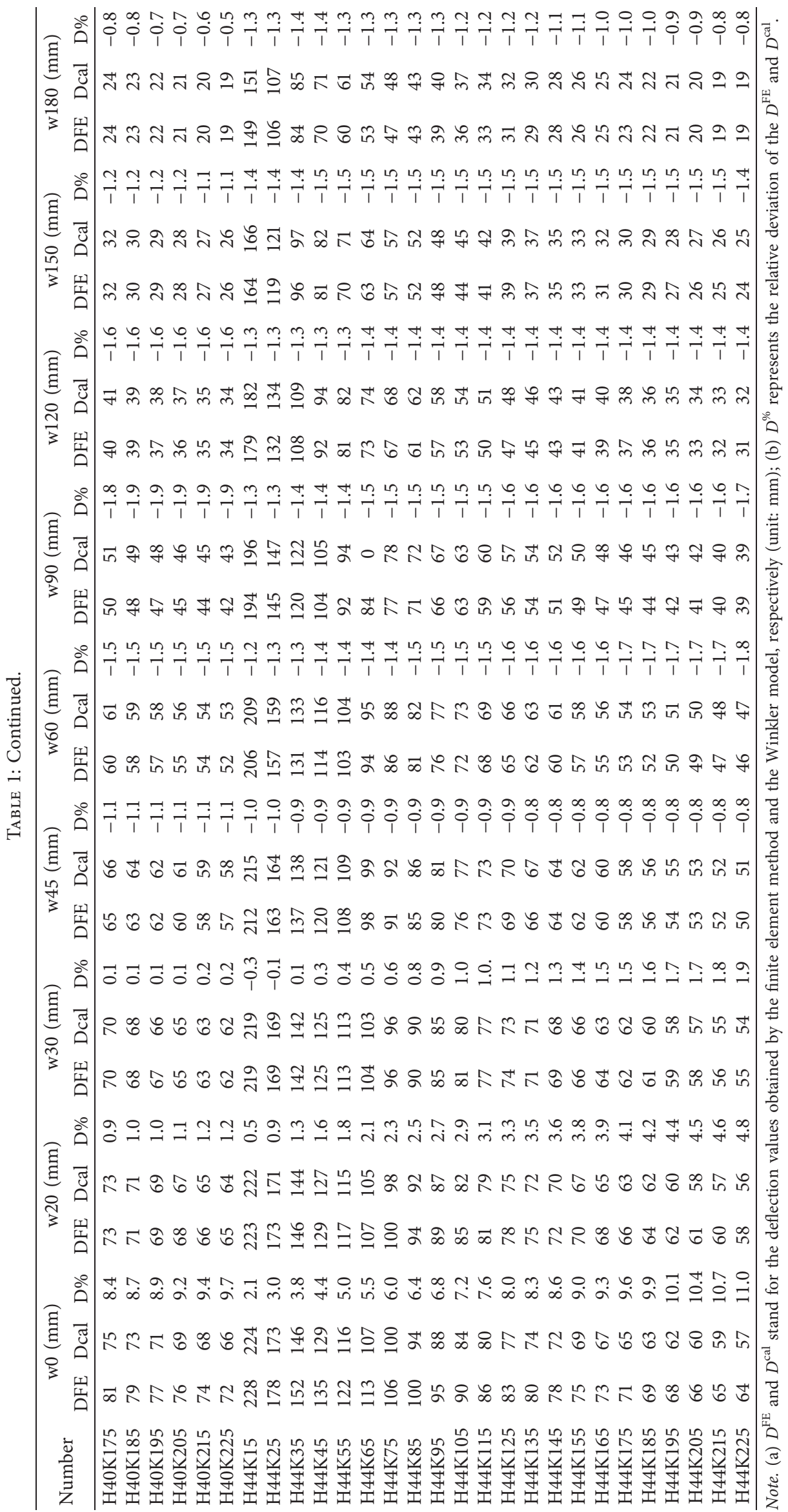




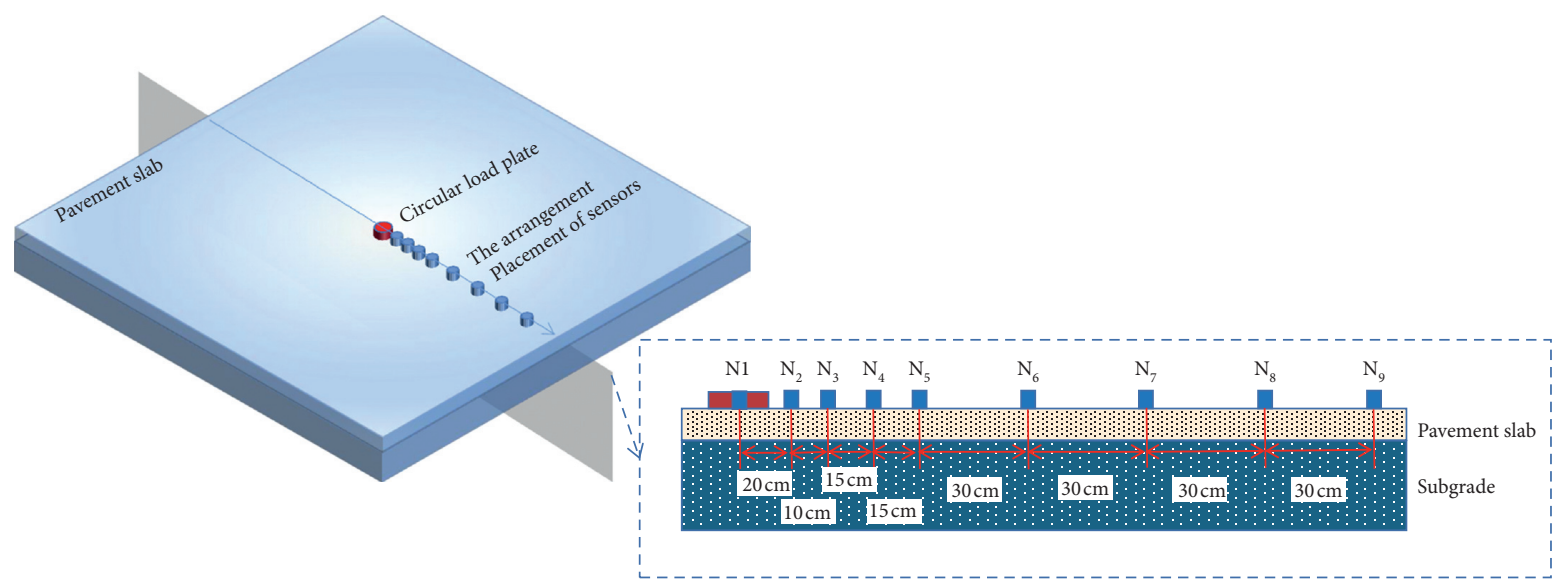

Figure 1: Layout of measuring points.

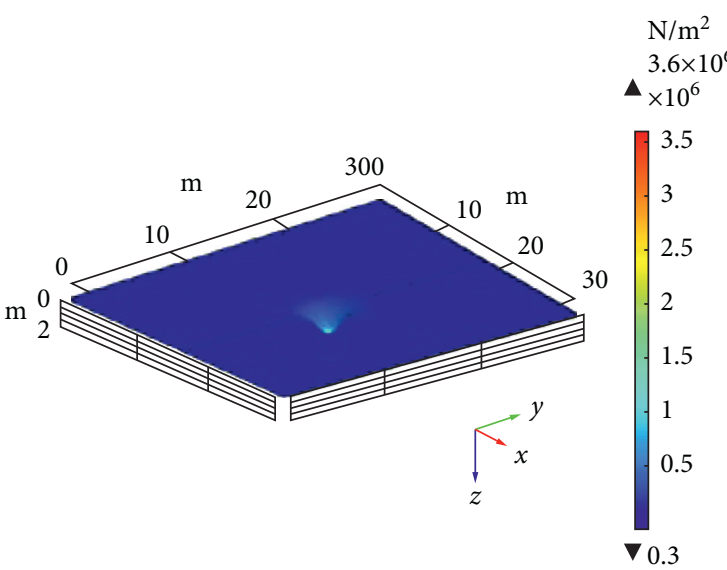

(a)

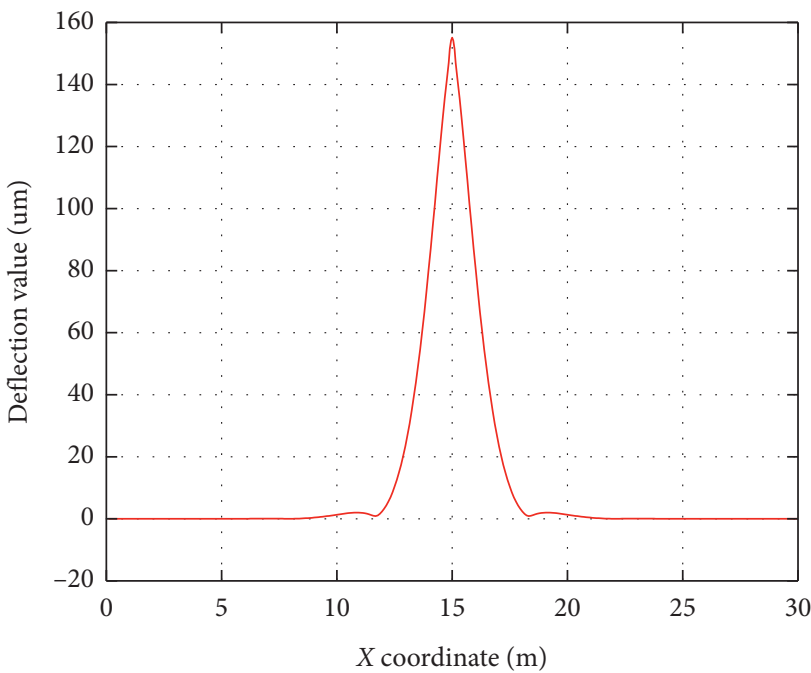

(b)

Figure 2: FE model of pavement thin slab. (a) Stress of concrete slab. (b) Displacement under H28K125 working condition.

Table 2: Parameters adopted in the parametric study.

\begin{tabular}{lc}
\hline Parameter & \multicolumn{1}{c}{ Value } \\
\hline Slab thickness $h(\mathrm{~mm})$ & $20-44$ at an interval of 4 \\
$\begin{array}{l}\text { Modulus of subgrade reaction } \\
k\left(\mathrm{MN} / \mathrm{m}^{3}\right)\end{array}$ & $15-225$ at an interval of 10 \\
\hline
\end{tabular}

$$
w(r)=\frac{q R}{k l} \int_{0}^{\infty} \frac{J_{0}((r / l) t) J_{1}((R / l) t)}{1+t^{4}} \mathrm{~d} t
$$

where $w(r)$ represents the deflection value at the distance of $r$ away from the load center $(\mathrm{m}) ; q$ is the circular uniform load $(\mathrm{Pa}) ; R$ stands for the radius of load acting surface $(\mathrm{m}) ; l$ represents the radius of relative stiffness $(\mathrm{m})$, which can be calculated by equation (2) according to Ioannides [12]; $J_{0}$ is the zero-order Bessel function; $J_{1}$ is the first-order Bessel function; $r$ is the distance of a measurement point away from the load center $(\mathrm{m})$; and $t$ stands for the integral variable.

$$
l=\left(\frac{E h^{3}}{12\left(1-\mu^{2}\right) k}\right)^{1 / 4}
$$

where $E$ represents the elastic modulus of pavement slab $(\mathrm{Pa})$ and $\mu$ represents Poisson's ratio.

2.4.2. Verification. To evaluate the accuracy of the FE model, the $\mathrm{FE}$ results were compared with the corresponding theoretical deflection values calculated with MATLAB under 154 working conditions according to the Winkler foundation model formula, as shown in Table 1. Only part of deflection data were selected to illustrate the difference of theoretical and simulated value of deflections, as depicted in Figure 3. The variables $D^{\mathrm{FE}}$ and $D^{\mathrm{cal}}$ represent the deflection values obtained by the numerical simulation and theoretical calculation, respectively. 


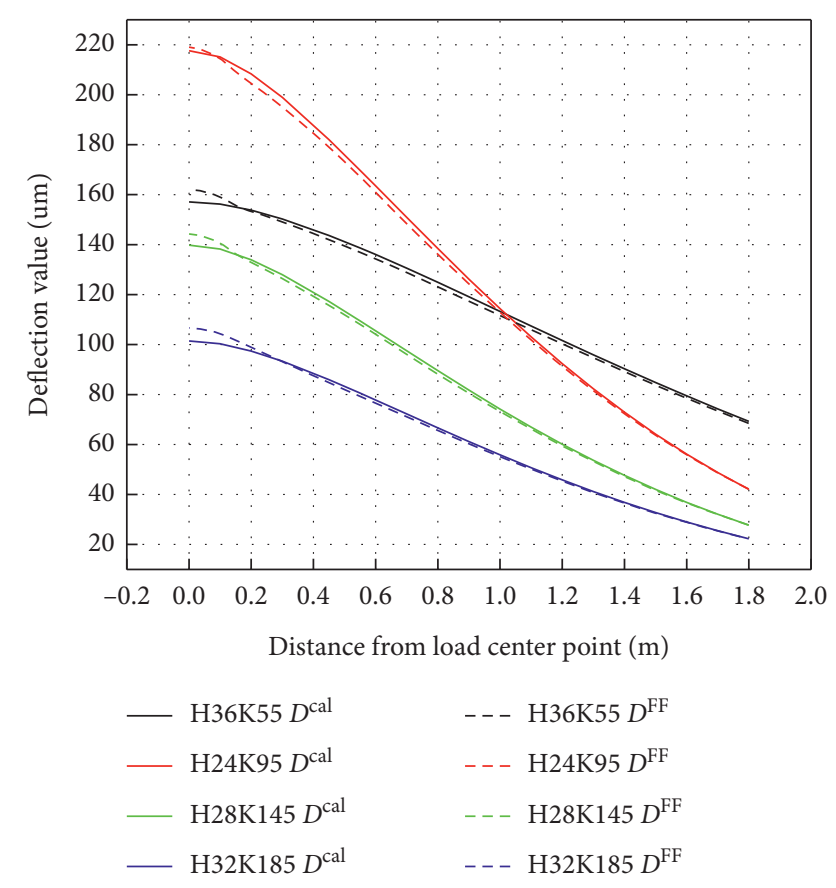

FIgUre 3: Comparisons of deflections between FE simulations and theoretical calculations.

It can be seen from Table 1 and Figure 3 that the difference between the simulated value and the theoretical value is rather small, and the deviations of the points within $20-150 \mathrm{~cm}$ away from the load center are even lower than $5 \%$. Moreover, the deviation decreases first and then increases with the increment of slab thickness, and it increases with the modulus of subgrade reaction. For the slab with a thickness of $0.24-0.40 \mathrm{~m}$, the deviations are all lower than $10 \%$. However, when the slab thickness exceeds or is lower than a specific value and with the increment of the modulus of subgrade reaction, the deviation between the two methods gradually increases. For example, when the thickness of the slab is $0.44 \mathrm{~m}$, the maximum deviation of the measurement point in the load center is $10.96 \%$, and the deviation of the measuring point at the location of $180 \mathrm{~cm}$ away from the load center is $11.82 \%$ on the slab with the thickness of $0.2 \mathrm{~m}$. The reason is probably that the Winkler foundation model was initially developed based on the thin slab theory, and the thick slab may be squeezed vertically at the loading point, resulting in the measurement deviation. The accuracy of the predicted solution may be extensively degraded for the slab with a relatively high modulus of subgrade reaction. Furthermore, there was no interaction between different points, as assumed in the Winkler foundation model. However, weak interactions can be detected in the FE model. When the thickness of the slab was relatively thin, the cumulative deviation may bring a significant error for the farthest point away from the loading point with the increase of the modulus of subgrade reaction due to the weak interaction. Therefore, to ensure the accuracy of verification and the rationality of the model parameters being relative to the engineering application, it is suggested that the optimal range of the slab thickness is $0.24-0.40 \mathrm{~m}$.

\section{Refined Deflection Basin Area Index Method}

3.1. General Description. Ioannides [12] has illustrated that the deflection basin area index $A_{w}$ (see equation (3)) was a geometric property of the deflection basin, which can be calculated based on the by dividing the basin into several fine trapezoids as shown in Figure 4. Then, $A_{w}$ is normalized by the deflection value $w$ of the designated measuring point, which can be applied to describe the geometric information of the deflection basin:

$$
A_{w}=\frac{s}{2 w}\left[w_{0}+2\left(w_{1}+w_{2}+\cdots w_{n-1}\right)+w_{n}\right]
$$

where $s$ represents the distance between two adjacent measuring points $(\mathrm{m}) ; w$ is the deflection of the designated measuring point $(\mathrm{m})$; and $w_{i}$ is the deflection of measuring point $i(\mathrm{~m})$.

Based on the elastic foundation slab model theory, the deflection basin area index method is a back-calculation approach that determines the pavement structural parameters as per the deflection value. The back-calculation process can be stated as follows. According to equations (1) and (2), the deflection value at a certain point is determined by the calculations of $q R / k$ and $1 / l \int_{0}^{\infty}\left(J_{0}((r / l) t) J_{1}((R / l) t) / 1+t^{4}\right) \mathrm{d} t$. However, it is difficult to calculate the modulus of subgrade reaction $k$ and the radius of relative stiffness $l$ in practical engineering simultaneously. To separate these two variables, the deflection basin area index $A_{w}$ becomes a necessity, and the relationship between $A_{w}$ and $l$ can be established. Then, according to the expression of the deflection coefficient $w(l)$, the equations of the modulus of subgrade reaction $k$ and the elastic modulus of pavement slab $E$ are also available, which are induced by the following equations:

$$
k=\frac{q R}{w\left(r_{0}\right)} w(l)
$$

where $w\left(r_{0}\right)$ is the deflection value at $r_{0}$ away from the load center $(\mathrm{m})$ and $w(l)$ stands for deflection coefficient which is equal to $1 / l \int_{0}^{\infty}\left(J_{0}((r / l) t) J_{1}((R / l) t) /\left(1+t^{4}\right)\right) \mathrm{d} t$.

$$
E=\frac{12\left(1-\mu^{2}\right) k l^{4}}{h^{3}} \text {. }
$$

\subsection{Existing Deflection Basin Area Index Methods}

3.2.1. Method Introduction. So far, the conventional deflection basin area index methods with satisfactory accuracy mainly include MH/T 5024-2009 [13], Strategic Highway Research Program (SHRP) 4-in, SHRP 5-outer, US Air Force (USAF) 6-outer, and SHRP 7-in method [24]. It should be noted that the number represents the number of measuring points, and the following label of "in" and "outer" means the near-side measuring points (measurement ranges within the load center) and far-side measuring points (measurement ranges beyond the load center), respectively. Figure 5 shows the layout schemes of measuring points of several theories mentioned above. 


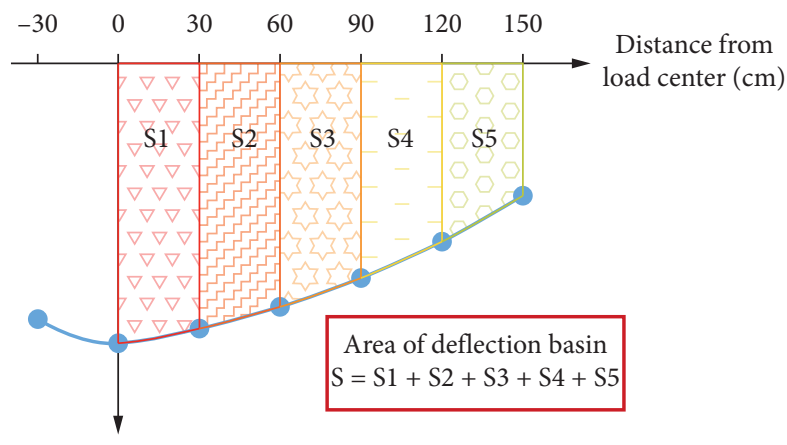

Deflection value $(\mu \mathrm{m})$

Figure 4: Calculation diagram of the deflection basin area.

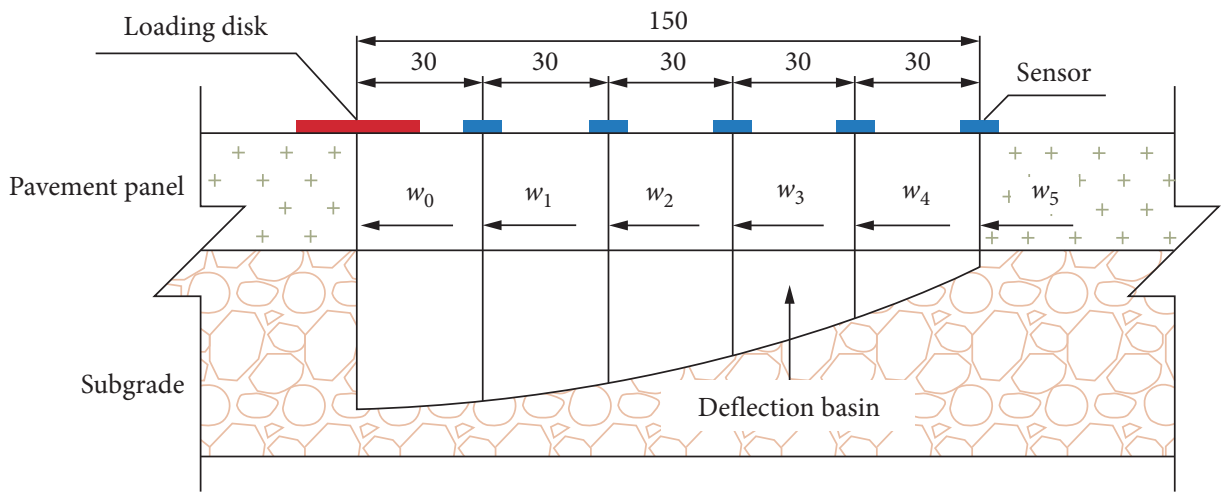

(a)

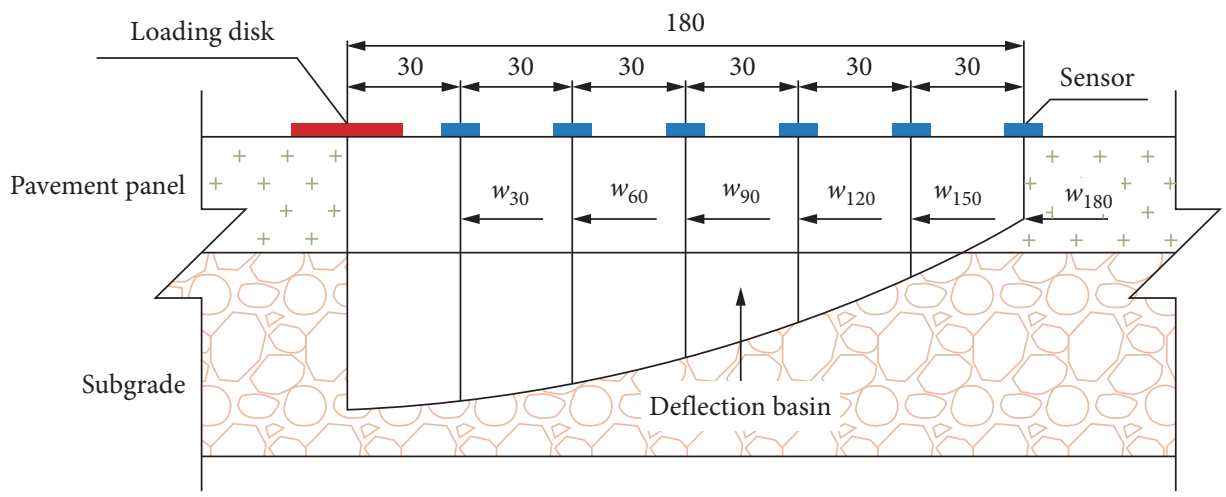

(b)

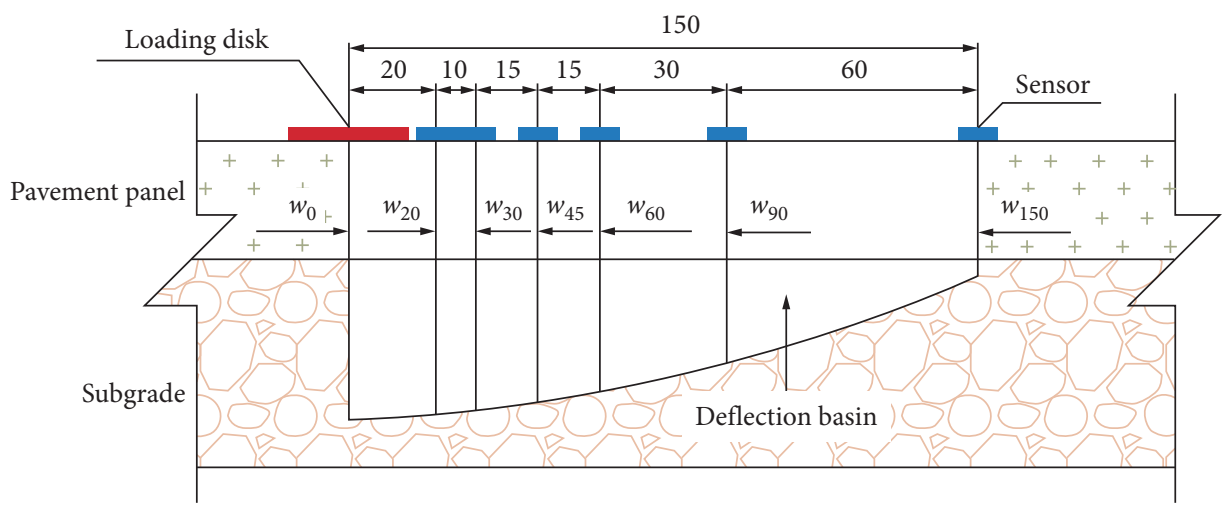

(c)

FigURE 5: Layout schemes of measuring points. Layout scheme of (a) MH/T 5024-2009 [13], (b) Cheng et al. [19], and (c) SHRP 7-in [24]. 
Cheng et al. [19] have analyzed the accuracy of backcalculation of the five deflection basin area index methods mentioned above for pavement structural parameters and reported that the results of the far-end measuring points were more accurate. Furthermore, it has also been observed that sufficient measuring points and a reasonable form of best-fitting formula can significantly improve the accuracy of prediction. In addition, for the reason that most of the existing methods cannot incorporate the deflection information of each measurement point, Lin et al. [15] developed a revised deflection basin area index method to overcome this deficiency using the point-by-point fitting method [9] based on the traditional deflection basin area index method. The results revealed that the new method can provide more reasonable back-calculation results. However, this method requires multiple iterations of the distribution, which makes the calculation process quite complicated.

3.2.2. Method Evaluation. Based on the database mentioned above, the accuracy of the methods of MH/T 5024-2009 [13], SHRP 7-in [24], Cheng et al. [19], and Lin et al. [15] is systematically evaluated in this section. Nine groups of representative working conditions are compared. The results are presented in Figure 6 and Table 3. It should be noted that the calculated value of the modulus of subgrade reaction $k$ is adopted to assess the accuracy.

As illustrated in Figure 6, although the methods of SHRP 7-in [24] and MH/T 5024-2009 [13] adopted similar layout schemes on the near-end measuring points, smaller backcalculation deviations are detected for the former method. This is because that the measuring points in SHRP 7-in [24] method are arranged intensively near the loading point, where the slope of deflection basin curve is significantly changed to fully capture the shape of deflection basin, resulting in a higher accuracy compared with $\mathrm{MH} / \mathrm{T}$ 50242009 [13]. Since the far-end measuring points were used in Cheng et al. [19] method to conduct the back-calculation process, the predicted errors decrease obviously due to the reason stated before. For these methods except for Lin et al. [15], the deflection value of a specific measuring point was applied to standardize the deflection basin area index $A_{w}$. Thus, when the information of the specific measuring point is inaccurate, considerable errors of the predicted results may emerge, and the back-calculation process may become unstable as well. Moreover, if the deflection value normalizes the deflection basin area index at different measuring points, multiple-solution problems need to be considered as well. To avoid these potential problems, Lin et al. [15] have calculated the back-calculation results by minimizing the deviations as the objective function, which exhibits the best performance among all selected methods, as represented in Figure 6. However, low efficiency and complex calculations faced by this method means that it cannot be applied directly in practical engineering.

3.3. Proposed Method. To balance the accuracy of prediction and calculation complexity, seven locally intensive far-end measuring points were adopted with the positions of $30 \mathrm{~cm}$,
$45 \mathrm{~cm}, 60 \mathrm{~cm}, 90 \mathrm{~cm}, 120 \mathrm{~cm}, 150 \mathrm{~cm}$, and $180 \mathrm{~cm}$ away from the load center, as shown in Figure 7 . Besides, the average $\bar{w}$ of all the above points was applied directly to determine the deflection basin area index $A_{w}$ and the resulting modulus of subgrade reaction $k$ was recalculated as well (equations (6)-(8)). The most evident advantage of this method was that the information of deflection of all measuring points can be considered to make the predicted results more accurate and stable and to avoid the multiple-solution problem effectively.

$$
A_{w}=\frac{0.15}{2 \bar{w}}\left[w_{30}+2 w_{45}+3 w_{60}+4\left(w_{90}+w_{120}+w_{150}\right)+2 w_{180}\right] \text {, }
$$

where $w_{j}$ is the deflection of measuring point $j(\mathrm{~m})$ and $j$ represents the distance from the load center $(\mathrm{m})$.

$$
\begin{aligned}
\bar{w} & =\frac{1}{7}\left(w_{30}+w_{45}+w_{60}+w_{90}+w_{120}+w_{150}+w_{180}\right), \\
k & =\frac{q R}{\bar{w}} w(l) .
\end{aligned}
$$

Based on the deflection results from FE simulations under different working conditions (including different modulus of subgrade reaction $k$ and different thickness of pavement slab $h$ ), the expression on the radius of relative stiffness $l$ was obtained by regression analyses [25] with equations (2) and (6), as presented in equation (9); next, the deflection coefficient $w(l)$ was regressed through equations (8)-(9), as presented in equation (10). Figures 8 and 9 show that the trend almost coincides with the simulation results with $R^{2}$ being equal to 0.9927 and 0.9995 , respectively. It should be noted that, under all working conditions, the deflection results of the slab with a certain thickness are represented by the same label, and the number following the letter " $H$ " refers to the thickness of the slab. $X$ represents all working conditions under this plate thickness.

$$
\begin{array}{r}
l=0.0036 e^{\left(A_{w}^{4.60338}\right)}+0.52495 \\
w(l)=0.1945 e^{(-1.90595 l)}+0.00908 .
\end{array}
$$

\section{Comparison with Engineering Data}

4.1. Data Source. An airport in northern China was selected to obtain practical deflection results. The runway is $2200 \mathrm{~m}$ in length and $45 \mathrm{~m}$ in width, including two vertical contact lanes and six parking aprons. The airport is located on the frozen soil area, and the soil layers are topsoil/miscellaneous fill, fine sand, silty clay, and bedrock (moderately and strongly weathered granite) [26], respectively. The runway of the airport has a severe frost boiling problem due to the freeze-thaw effect and constant impact loads. Thus, the HWD deflection test has been carried out on the existing pavement to assess the safety grade of the airport, as shown in Figure 10, which covered all functional regions, as listed in Table 4. 


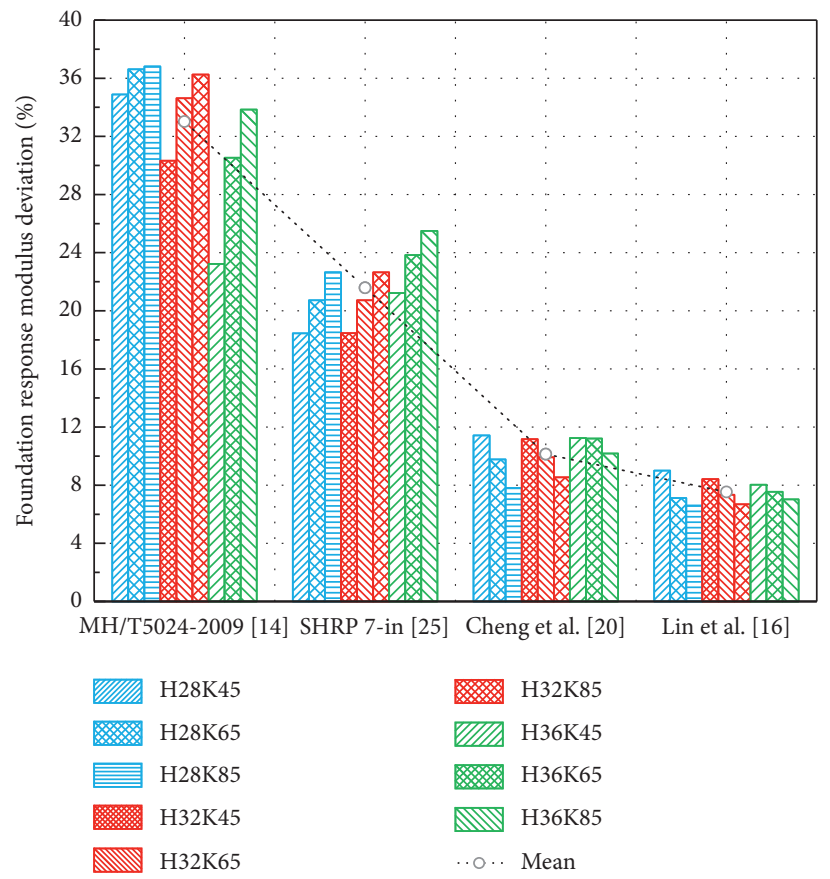

FIGURE 6: Deviation comparison of existing deflection basin area index methods.

TABLE 3: Comparison of existing deflection basin area index methods.

\begin{tabular}{lcccc}
\hline Number & MH/T 5024-2009 [13] (\%) & SHRP 7-in [24] (\%) & Cheng et al. [19] (\%) & Lin et al. [15] (\%) \\
\hline H28K45 & 34.89 & 18.45 & 11.43 & 9.01 \\
H28K65 & 36.62 & 20.72 & 9.77 & 7.8 \\
H28K85 & 36.81 & 22.65 & 11.16 & 6.59 \\
H32K45 & 30.33 & 18.46 & 9.92 & 8.42 \\
H32K65 & 34.63 & 20.72 & 8.54 & 7.34 \\
H32K85 & 36.26 & 22.65 & 11.25 & 8.69 \\
H36K45 & 23.22 & 21.22 & 11.21 & 7.03 \\
H36K65 & 30.53 & 23.83 & 10.18 & 7.02 \\
H36K85 & 33.85 & 25.50 & 10.38 & 7.51 \\
Average & 33.02 & 22.06 & & \\
\hline
\end{tabular}

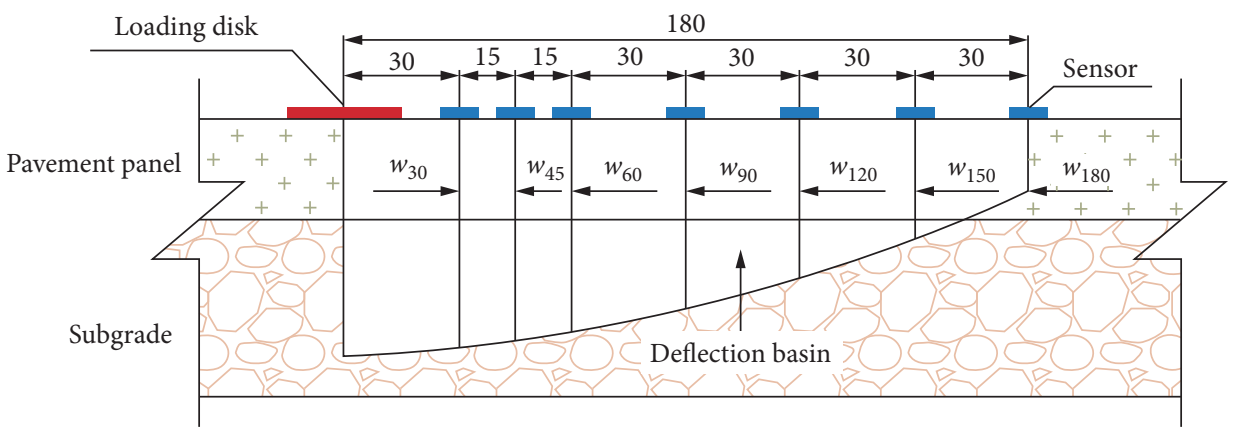

FIGURE 7: Layout scheme of measuring points in the proposed method.

4.2. Verification Results. To verify the rationality of the proposed method, the actual deflection data of each functional area of the airport were randomly selected to examine the back-calculation accuracy of the new proposed approach and three other methods developed by MH/T 5024-2009 [13], Cheng et al. [19], and Lin et al. [15]. Based on the measuring data of deflections, the deflection basin area index $A_{w}$ can be determined by equation (6). Then, the radius of relative stiffness $l$ and the deflection coefficient $w(l)$ were obtained by the proposed equations as well, and the modulus of subgrade reaction $k$ and elastic modulus of pavement slab $E$ can also be derived by equations (8) and (5), respectively. 

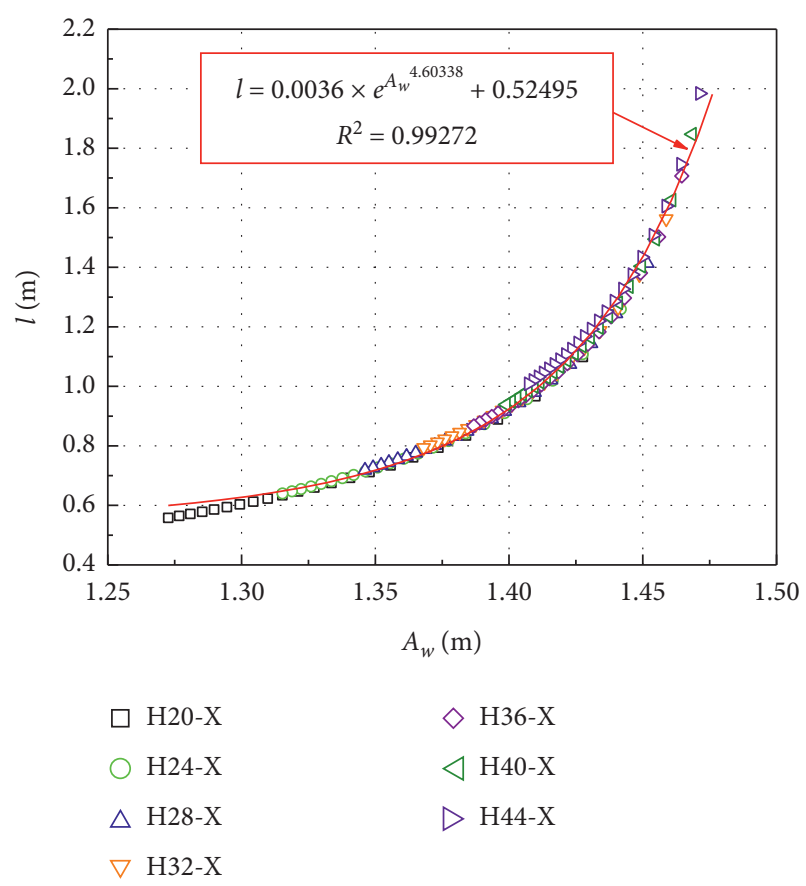

Figure 8: Relationship between $A_{w}$ and $l$.

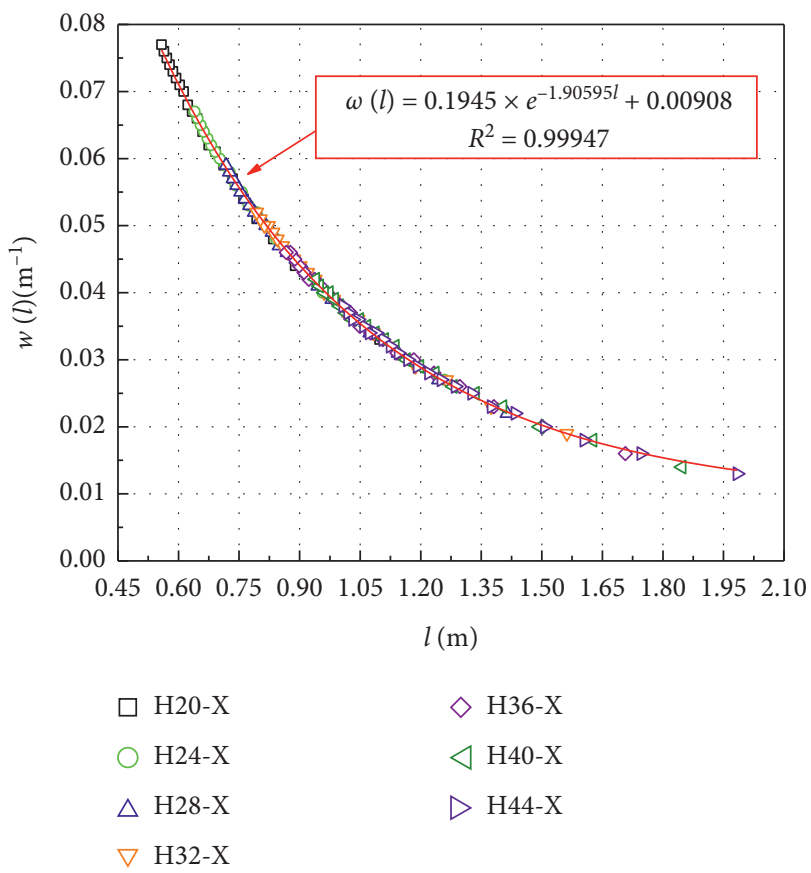

Figure 9: Relationship between $l$ and $w(l)$.

Therefore, the theoretical value of deflection calculated by equation (1) as per the above structural parameters was adopted to compare it with the actual measurement value, and the difference between the two values is shown in Figure 11 and Table 5.

As shown in Figure 11, the methods developed by Cheng et al. [19] and MH/T 5024-2009 [13] possess a lower accuracy and unstable predictions, which indicates that the information of the specific measuring point adopted to

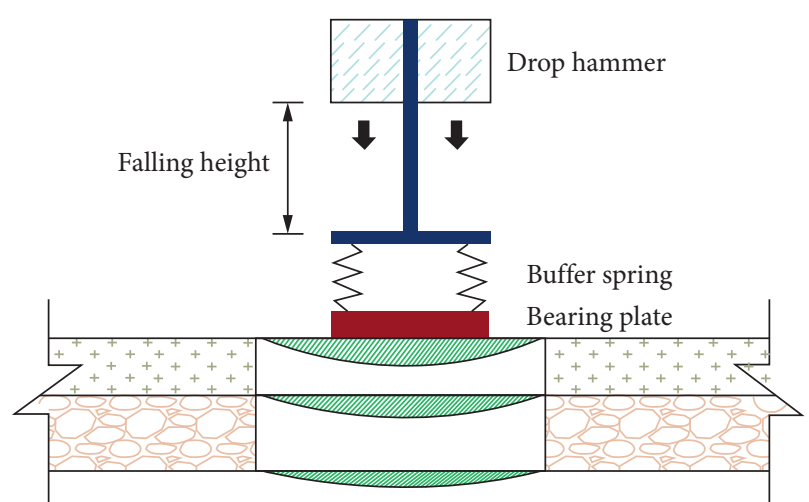

FIgURE 10: Schematic diagram of HWD deflection measurement.

TABLE 4: Information of pavement structure for the airport.

\begin{tabular}{lccc}
\hline Region & Functional area & Pavement type & Load $(\mathrm{kN})$ \\
\hline Runway & $\begin{array}{c}1800 \mathrm{~m} \text { from east to } \\
\text { west } \\
\text { 400 m from west to } \\
\text { east }\end{array}$ & $\begin{array}{c}\text { Cement } \\
\text { concrete }\end{array}$ & 70 \\
\hline Contact lane & $\begin{array}{l}\text { A contact lane } \\
\text { B contact lane }\end{array}$ & $\begin{array}{l}\text { Cement } \\
\text { concrete }\end{array}$ & 70 \\
\hline $\begin{array}{l}\text { Parking } \\
\text { apron }\end{array}$ & $\begin{array}{c}\text { A parking apron } \\
\text { B parking apron }\end{array}$ & $\begin{array}{l}\text { Cement } \\
\text { concrete }\end{array}$ & 70 \\
\hline
\end{tabular}

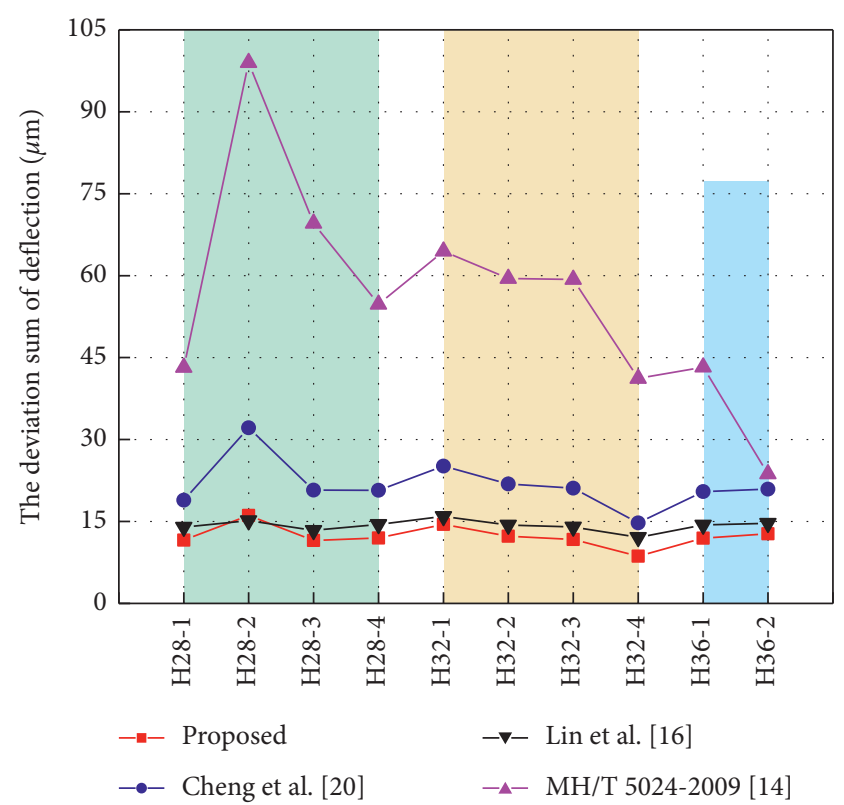

FIgURE 11: The deviation sum of deflection.

standardize $A_{w}$ may have a great impact on the back-calculation results in the conventional deflection basin area index methods. For the proposed method and method developed by Lin et al. [15], more stable results can be obtained because all measuring points are considered. Moreover, the new method proposed in this study exhibits the better performance with the lower predicted errors and 


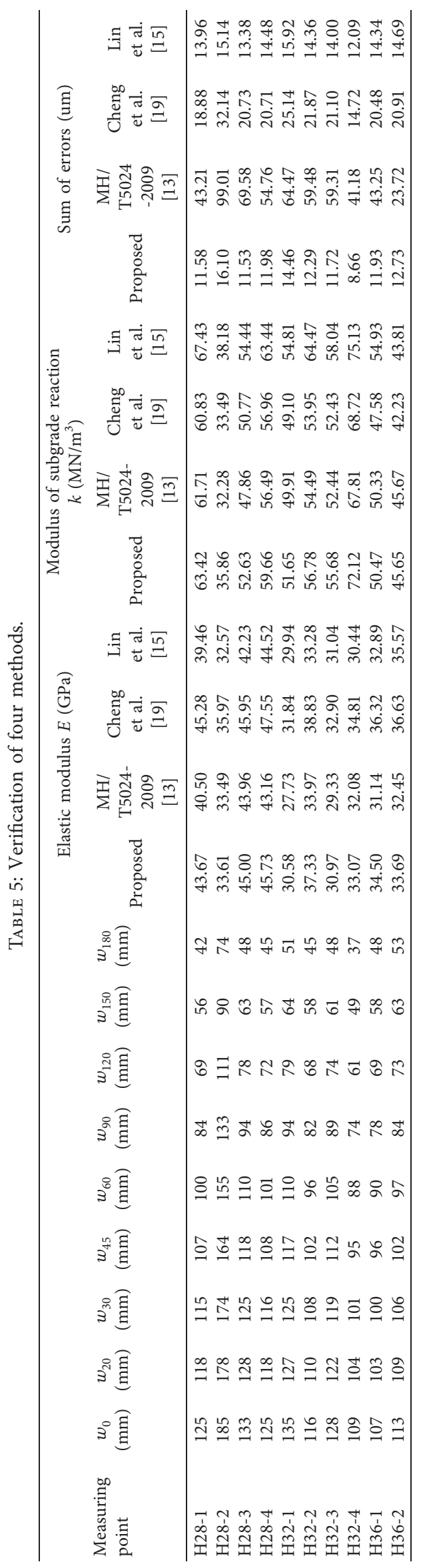


higher computed efficiency compared with the method developed by Lin et al. [15], which is more convenient for the practical engineering application.

\section{Conclusions}

FE modeling was adopted to simulate the pavement structure in this study, and the study on parameter was also carried out to develop a new deflection basin area index. The main conclusions that can be drawn as follows:

(1) By comparing the deflection values gained from FE simulation with the theoretical values calculated by the Winkler foundation response model, increasing deviations are observed with the increment of the modulus of the subgrade reaction when the pavement slab is either too thick or thin. Thus, considering the accuracy of the FE method and the actual demands of practical engineering, the suitable range of slab thickness for pavement structural parameters in the back-calculation process is suggested to be $0.24-0.4 \mathrm{~m}$.

(2) Based on the established database, the back-calculation results of several existing deflection basin area index methods reveal that the increase of local measuring points under the same layout scheme can improve the accuracy of back-calculation results. Moreover, using the average deflection of all measuring points instead of a specified point during the normalized procedure, the back-calculation will become more stable, and the multiple-solution problem can also be alleviated.

(3) According to the deflection database obtained by FE simulation under different working conditions, a refined deflection basin area index method is proposed. The actual measuring data from an airport in northern China is applied to verify the rationality of the new method. Comparisons between the test results and theoretical predictions illustrate that the new method possesses a higher accuracy and efficiency, which may provide valuable guidance for the practical engineering application.

\section{Data Availability}

The data used in this paper are all from the finite element simulation and engineering measurement mentioned in the study.

\section{Conflicts of Interest}

The authors declare that there are no conflicts of interest regarding the publication of this study.

\section{Acknowledgments}

This research was supported financially by the National Natural Science Foundation of China (grant no. 41702320).

\section{References}

[1] C. Guo and F. Wang, "Case study on quick treatment of voids under airport pavement by polymer grouting," Journal of Materials in Civil Engineering, vol. 32, no. 7, Article ID 05020006, 2020.

[2] K. Gopalakrishnan and M. R. Thompson, "Pavement moduli variation under heavy aircraft trafficking," Proceedings of the Institution of Civil Engineers-Transport, vol. 159, no. 3, pp. 117-125, 2006.

[3] J. Roussel, C. Sauzéat, H. D. Benedetto, and M. Broutin, "Numerical simulation of falling/heavy weight deflectometer test considering linear viscoelastic behaviour in bituminous layers and inertia effects," Road Materials and Pavement Design, vol. 20, pp. 1-15, 2019.

[4] M. Broutin and A. Sadoun, "Advanced modelling for rigid pavement assessment using HWD," Transportation Research Procedia, vol. 14, pp. 3572-3581, 2016.

[5] S. R. Amin and L. E. Amador-Jiménez, "Backpropagation neural network to estimate pavement performance: dealing with measurement errors," Road Materials and Pavement Design, vol. 18, no. 5, pp. 1218-1238, 2017.

[6] T. F. Fwa, C. Y. Tan, and W. T. Chan, "Backcalculation analysis of pavement-layer moduli using genetic algorithms," Transportation Research Record: Journal of the Transportation Research Board, vol. 1570, no. 1, pp. 134-142, 1997.

[7] K. Loganathan, M. M. Isied, A. M. Coca, M. I. Souliman, S. Romanoschi, and S. Dessouky, "Development of comprehensive deflection parameters to evaluate the structural capacity of flexible pavements at the network level," International Journal of Pavement Research and Technology, vol. 12, no. 4, pp. 347-355, 2019.

[8] E. Camacho-Garita, R. Puello-Bolaño, P. Laurent-Matamoros, J. P. Aguiar-Moya, and L. Loria-Salazar, "Structural analysis for APT sections based on deflection parameters," Transportation Research Record: Journal of the Transportation Research Board, vol. 2673, no. 3, pp. 313-322, 2019.

[9] M. I. Darter, K. T. Hall, and C. M. Kuo, Support under portland Cement concrete Pavements, Transportation Research Board, Washington, DC, USA, 1995.

[10] L. J. Sun, S. Hu, and X. N. Zhang, "Intertial point on deflection basin of concrete pavement and asphalt pavement," Journal of Highway and Transportation Research and Development, vol. 18, no. 3, pp. 1-5, 2001, in Chinese.

[11] J. Zhu and L. J. Sun, "Determination of optional backcalculation point for three layer structure modulus backcalculation of asphalt pavement," Journal of Tongji University, vol. 45, no. 2, pp. 203-208, 2017, in Chinese.

[12] A. M. Ioannides, "Dimensional analysis in NDT rigid pavement evaluation," Journal of Transportation Engineering, vol. 116, no. 1, pp. 23-36, 1989.

[13] CAAC (Civil Aviation Administration of China), Technical Specifications of Aerodrome Pavement Evaluation and Management MH/T 5024-2009, China Civil Aviation Publishing House, Beijing, China, 2009, in Chinese.

[14] AASHTO (American Association of State Highway Transportation Officials), AASHTO Guide for Design of Pavement Structures, AASHTO, Washington, DC, USA, 1993.

[15] X. P. Lin, J. Yuan, J. M. Ling, and Z.-M. Tan, "Improved deflection basin area parameters back calculation method for rigid pavement," China Journal of Highway and Transport, vol. 22, no. 3, pp. 14-19, 2009, in Chinese.

[16] J. M. Ling, S. F. Liu, and J. Yuan, "Improved AREA backcalculation method for rigid pavement and its regression 
model," Journal of Tongji University, vol. 46, no. 12, pp. 1683-1689, 2018, in Chinese.

[17] L. K. Ma, M. Li, J. S. Pang, and C. Huang, "Evaluation of transverse cracks for semi-rigid asphalt pavements using deflection basin parameters," Transportation Research Record: Journal of the Transportation Research Board, vol. 2673, no. 2, pp. 358-367, 2018.

[18] J. Xu, Z. Shen, S. Yang, X. Xie, and Z. Yang, "Finite element simulation of prevention thermal cracking in mass concrete," International Journal of Computing Science and Mathematics, vol. 10, no. 4, pp. 327-339, 2019.

[19] G. Y. Cheng, X. J. Wang, and M. Y. Liao, "Improvement of deflection basin area index method based on solid element," Journal of Highway and Transportation Research and Development, vol. 36, no. 4, pp. 15-20, 2019, in Chinese.

[20] R. S. Chen, B. M. Tang, and J. K. Qin, "Comparison of two foundation models under the rigid pavement slab," China Journal of Highway and Transport, vol. 3, no. 2, pp. 1-10, 1990, in Chinese.

[21] J. Yuan, Research on Parameters Back Calculation Method for Airport Rigid Pavements, Tongji University, Shanghai, China, 2008, in Chinese.

[22] MOHURD (Ministry of Housing and Urban-Rural Development of the People's Republic of China), Code for Geotechnical Investigations of Urban Rail Transit GB 50307-2012, China Planning Press, Beijing, China, 2012, in Chinese.

[23] R. R. Costigan and M. R. Thompson, "Response and performance of alternate launch and recovery surf aces that contain layers of stabilized material," Transportation Research Record, vol. 1986, pp. 57-71, 1986.

[24] US FAA (Federal Aviation Administration), Use of Nondestructive Testing in the Evaluation of Airport Pavements AC 150/5370-11B, US Department of Transportation, Washington, DC, USA, 2011.

[25] C. Zhu, M. He, M. Karakus, X. Zhang, and Z. Guo, "The collision experiment between rolling stones of different shapes and protective cushion in open-pit mines," Journal of Mountain Science, vol. 18, no. 5, pp. 1391-1403, 2021.

[26] Q. Yin, J. Y. Wu, C. Zhu, M. C. He, Q. X. Meng, and H. W. Jing, "Shear mechanical responses of sandstone exposed to high temperature under constant normal stiffness boundary conditions," Geomechanics and Geophysics for GeoEnergy and Geo-Resources, vol. 7, no. 2, 2021. 